\title{
THE BUILDING BLOCKS OF CONSULTING SERVICE EXCELLENCE
}

\author{
Adeline A. Pacia, Assistant Professor, Department of Industrial Engineering and \\ Operations Research, University of the Philippines Diliman
}

\begin{abstract}
Purpose: The objective of the study was to identify and address areas that will contribute to the competitive strategy of the service delivery group of a Knowledge Process Outsourcing (KPO) company whose business is focused mainly on the sales and implementation of Enterprise Resource Planning (ERP) solutions.

Design/methodology/approach: The DMAIC methodology was used in the study: Define, Measure, Analyze, Improve and Control.

Findings: For the company to be competitive, seven Building Blocks of Consulting Service Excellence were proposed: (a) Competency Framework which provides a guide for consultants in identifying key competencies needed to ensure high quality consulting service and career growth; (b) Implementation Methodology which serves as a guide for consultants in identifying key competencies needed to ensure high quality consulting service and career growth; (c) Solution Offerings and Value Proposition which are productized solutions specific to an industry or business process; (d) Human Resource Development which programs the skills development and career growth of the consultants; (e) Organization and Management which covers the organizational structure and management team needed to ensure smooth delivery of the service; (f) Infrastructure Support which includes hardware and software platform; and ( $g$ ) Performance and Rewards which provide a platform to ensure a motivated team committed to the company vision.

Originality/value: These Building Blocks provide a structure in ensuring an efficient Human Supply Chain - from personnel recruitment to human resource development to career transitions and retirement. As a Knowledge Process service provider, the quality of the company's employees is critical to both the success and key to its competitiveness, and the success of their partners and the clients it serves.
\end{abstract}

Category: Conceptual Paper

Keywords: Performance Measurement and Management, Knowledge Management, Human Resource Management, Competitive Strategy, Quality Improvement and Management, Organizational Development 


\section{Proceedings of 2013 International Conference on}

Technology Innovation and Industrial Management

29-31 May 2013, Phuket, Thailand

\section{INTRODUCTION}

\section{Background of the Study}

Knowledge Process Outsourcing (KPO) is now an emerging sector that promises to provide long-term jobs for intellectual, analytical and knowledgeable people with pay scales much higher than that offered in the business process outsourcing sector (Buban, 2013). KPO is defined as the "allocation of relatively high-level tasks to an outside organization or a different group in a different geographic location" (Investopedia, 2013).

A KPO company is a consulting service organization in which knowledge- and informationrelated work is carried out by workers in a different company or by a subsidiary of the same organization. This subsidiary may be in the same country or in an offshore location to save costs or other resources. Companies resort to KPO when they have a shortage of skilled professionals and have the opportunity to hire skilled workers earning lower wages in another location for a lower overall cost. KPO include long-term jobs for intellectual, analytical and knowledgeable people within industries such as research and development, financial consultancy and services, business and technical analysis among others (Investopedia, 2013).

An Enterprise Resource Planning (ERP) solution implementation company is an example of a KPO focused on IT consulting services. For an ERP solutions implementation company, strategy must go beyond simply improving efficiency.

Competitive strategy refers to how a company competes in a particular business. It is concerned with how a company can gain a competitive advantage through a distinctive of competing (Harvard Business School, n.d.). Competitive strategy should address areas of customer care, speed and quality. These will differentiate the company's service delivery from its competitors. The competitive strategies identified cover inputs, processes, outputs and the organizational development activities across these three.

\section{Objective of the Study}

The study aims to identify and address areas that will contribute to the competitive strategy of a KPO Company whose business is focused mainly on the sales and implementation of ERP solutions.

As an ERP solutions implementation company, the study took into consideration the different technologies and service offerings, the structures and accompanying policies for the service activities, and the organizational development plans to support and complement the different technologies. Initial implementationwas tested on the SAP Business Solution. It can be applied $t$ other technology-enabledBusiness Solutions of an ERP solution implementation company. 


\section{Significance of the Study}

Organizational Development (OD) is the process through which an organization designs, creates, and builds physical and logical structures and processes,that will link together and combine all the actual and potential resources that will enable it to perform its functions and deliver its mission. OD develops the internal capacity to be the most effective in its mission work and sustain itself over the long term (MMS Institute, 2013). Input from and collaboration with partner organizations and clients in the company's Organization Development initiatives will bring competitive advantage.

The value of this study is to provide a structure in ensuring that the physical and logical structures and processes of the company are in place. As a Knowledge Process service provider, it is imperative to institute an efficient Human Supply Chain - from personnel recruitment to human resource development to career transitions and retirement. The quality of its consultants/employees is critical to the success of the company and key to its competitiveness. A competency-based recruitment and selection process increases the success rate of personnel hiring, training and regularization to full-time employees. It also provides an objective process of selecting candidates for career advancement and promotions. Likewise, the support infrastructure needed to complement the Human Supply Chain is also identified and defined.

\section{OPERATIONAL CHALLENGES}

As a Knowledge Process Outsourcing company, its principal operations are highly dependent on human resources. The depth and breadth of the consultants' skills are critical inputs to the successful delivery of the company's services. The main challenge to a Knowledge Process Outsourcing company is ensuring a smooth and efficient Human Supply Chain and a strong support infrastructure.

\section{Human Supply Chain}

The following issues are symptomatic of the real problem on Human Supply Chain:

1. To optimize opportunities, consultants are sometimes sent to projects even without the proper skills training required for the project. Consultants are sometimes forced to learn on the job;

2. Consultants are shared among several projects without clear schedules and guidelines;

3. Consultants assigned to projects are sometimes asked to address Application Support issues of other projects as well;

4. The skilllevels of consultantsare not always aligned with the skills required in the delivery of the project;

5. Extended work hours of the consultants;

6. Re-work or back jobs that affect the project schedules;

7. High burn-out rate of consultants; and

8. High attrition rate. 


\section{Proceedings of 2013 International Conference on}

Technology Innovation and Industrial Management

29-31 May 2013, Phuket, Thailand

Evaluating these symptomatic issues through the lessons learned in each project, the skills and process gaps identified were:

1. Lack of a structured assessment tool to identify the current competencies of the consultants and the gaps from what is needed by the project;

2. No concrete Training Plan to address the gaps in skill sets; and

3. Inadequate Resource Loading and Resource Management.

These problems can be addressed through the implementation of a Competency Framework and a clear Human Resource Development Plan. The Competency Framework identifies the key competencies required for the different roles and levels in the organization. It provides a tool to assess the individual's competency level and gaps in order to identify the necessary training to address the gaps. With a more accurate assessment of competencies and competency gaps, resource loading can be better planned and managed.

\section{Support Infrastructure}

The following issues are symptomatic of the problems on Support Infrastructure for an ERP Solutions Implementation company:

1. Inconsistency in the implementation processes among projects resulting to varying implementation timelines for similarly-scoped projects;

2. Frequent project implementation delays;

3. Delays sometimes due to lack of available equipment or delayed delivery of system infrastructure;

4. Similar projects are implemented from scratch because lessons learned from past projects are not acted upon to prevent the occurrence of past mistakes, which in turn makes project implementation vulnerable to and dependent on the skill level of the consultants;

5. Over-commitment of sales people on the project deliverables in order to make the sale;

6. Variable or reduced profit per project; and

7. Delayed billing and collection due to lack of triggers in the system and processes.

Evaluating these issues, the following possible gaps were identified:

1. Lack of structured project implementation methodology to ensure consistency and timeliness of process execution;

2. Opportunity to standardize solutions delivery offerings from lessons learned in previous implementations not maximized;

3. No clear performance assessment and rewards system to highly encourage quality and timely project implementations with managed customer expectations; and

4. Planning and forecasting for hardware and software requirements can be improved to ensure availability of support infrastructure in a timely manner.

These issues can be address by putting the support infrastructures in place. These would include the implementation methodology; standardized implementation packages for specific industries or business processes; packaged hardware, software and network components of the system architecture and the solution implementation team per solution offering. 


\section{THE BUILDING BLOCKS OF CONSULTING SERVICE EXCELLENCE}

The study proposes the development of a competitive framework for an ERP Solutions Implementation company. Entitled "The Building Blocks of Consulting Service Excellence"(Figure 1), it will cover the seven areas.

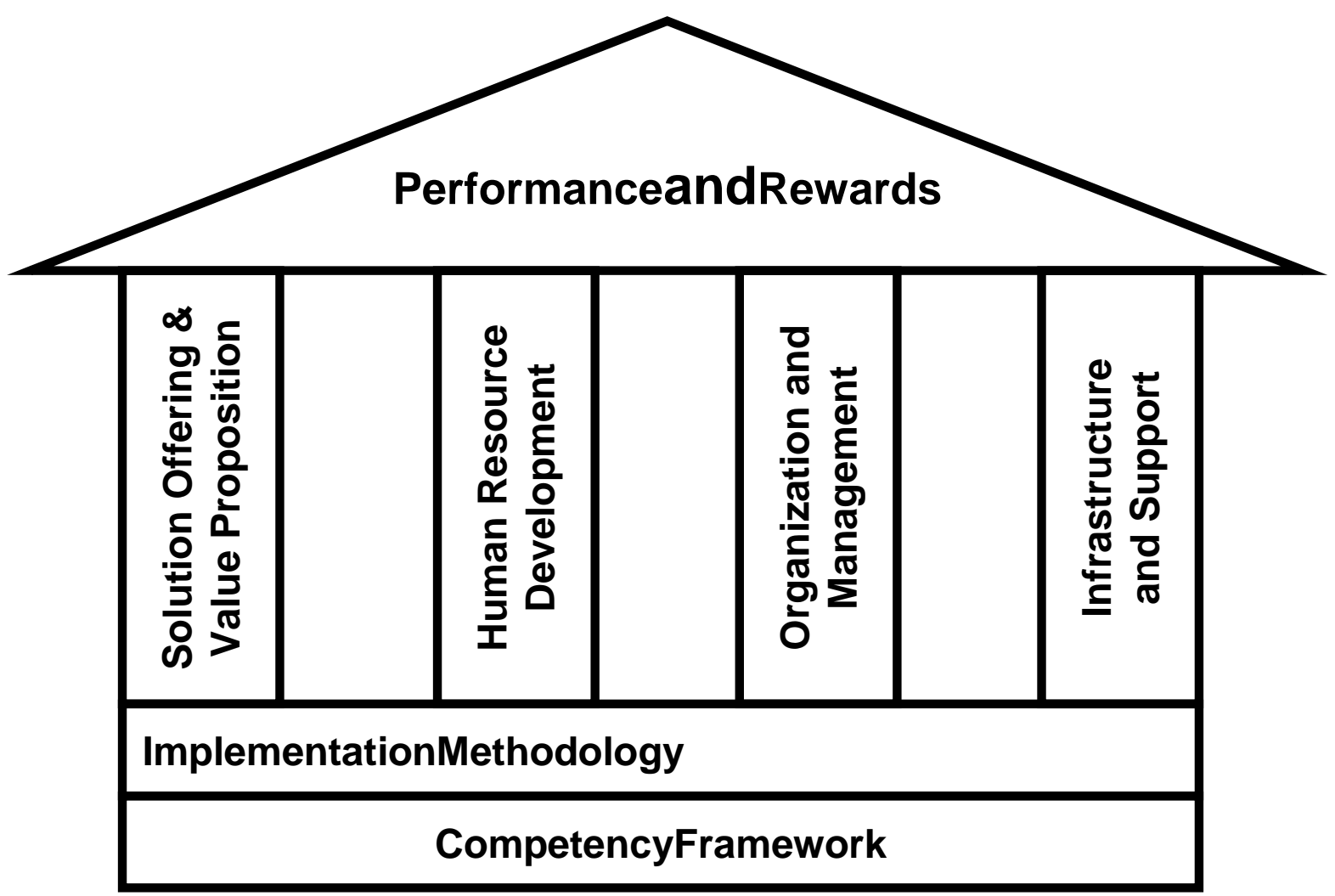

Figure 1. The Building Blocks of Consulting Service Excellence

\section{Competency Framework}

The Competency Framework is an approach to link company objectives to individual performance and should be part of the company's organization development initiative. This will provide a guide for the consultants in identifying key competencies needed to ensure high quality consulting service and career growth. This is a key component of the organizational development work needed to bring the consultants/employees to the skill level required to deliver quality service.

As the Competency Framework sits at the core of the program and lays the foundation of the Building Blocks and the entire infrastructure, it is the critical input to the processes and output of Competitive Strategy. Its principal operations are highly dependent on human resources. As a consulting company delivering process consulting, system implementation and support services 
in partnership with their clients and their respective teams, their clients' own human resources are also critical in the success of company's service delivery. The depth and breadth of the consultants' and project team's skills are critical inputs to the successful delivery of the company's services. Thus, the Competency Framework will cover the following:

- Competency Framework Concept

- Competency Tracks

- Assessment and Upgrade Policies

- Cross-Track Assessment

The Competency Framework not only identifies the competencies within the process areas and functions across the implementation methodology, it also provides a structure to move up the competency ladder. The competency-based Performance Management and Career Development Programsupports and reinforces the Competency Framework. Its rationale is to take performance management a step forward towards increasing the competitiveness of the firm in terms of increased speed and high quality of service to its clients.

\section{Human Resource Development}

Organizational development to ensure high quality consultants will deliver high quality work output. This programs the skills development and proficiency needed to move from one level to the next and is tightly knit with the Competency Framework. Each training and certification requirement is a step forward to the next competency level.

- Training Plan

- Certification Requirements

- Career Development

\section{Organization and Management}

The organization should be set-up to ensure focus on customer service and customer care. It should be the consultants' top of mind to serve the customer with fast quality service. Teams will be identified to support identified solution sets and customer group. It includes the organizational structure and the management team needed to ensure smooth operations in the delivery of service.

- Organizational Chart

- Management Team

- Policies

\section{Implementation Methodology}

The company will develop its own implementation methodology that is an enhanced version of the standard methodology of the given technology. Picking up from all the lessons learned from past implementation experience, it will identify key differentiators to ensure a faster delivery cycle, higher quality service and client ownership of the system at the onset. This details the phases and activities and the corresponding deliverables and Quality Assurance checkpoints to 
complete the implementation project from hand-over from Sales to Delivery and then hand-over to Support. The implementation methodology covers the processes to ensure a successful project implementation.

- Sales and Marketing

- Enterprise Solution Delivery

- Packaged Solution Delivery

- Post-implementation Application Support

\section{Solution Offerings and Value Proposition}

The focus of solution development efforts will be on productizing solutions specific to an industry or business process. Productization entails customizing the system to address specific needs of an industry, packaging the solution for proper sales and market positioning, setting up templates for fast and repeatable implementation success and ease of support after the implementation. This will ensure quality delivery from sales and marketing to delivery and support. It also covers corresponding pricing strategies for each set of solution offerings. The following are the strategic output from the technology (input) and the implementation Methodology (process):

- Solution Offerings

- Solution Map

- Industry Roadmaps

\section{Infrastructure and Support}

This identifies the strategic infrastructure support needed for product development, operational efficiencies, system and information security, knowledge management. This covers the support processes needed to efficiently deliver service, recognize and book revenue, and effectively collect payment when due. It also includes the hardware, software and network infrastructure needed to support the delivery team in their research and development activities and project implementation activities.

- System Development Landscape

- Production System Landscape

○ Internal Systems

○ Applications Support

\section{Performance and Rewards}

This provides a platform to ensure a motivated team committed to the company vision, goals and objectives and the individuals' self-fulfillment.

- Key Performance Indicators

- Upgrade, Promotion and Merit Increase Policies

- Other Recognition and Rewards 


\section{ADDRESING THE HUMAN SUPPLY CHAIN ISSUES}

The main challenges of consulting companies lies in the human supply chain, from recruitment to development, career transitions and retirement. The key components of the proposed Building Blocks of Consulting Service Excellence addressing the human supply chain issues are The Competency Framework and Human Resource Development.Human Resource Development includes (1) Career Bands and Career Zones, (2) The Job Design and (3) the Training Plan.

\section{The Competency Framework}

The Competency Framework has been used by successful global consulting companies for many years. IBM and Accenture, two of the leading It Consulting companies and large global players, have been using the Competency Framework for over 12 years already.

The proposed general framework identifies the competencies for each function within the Implementation Methodology. It covers the competency requirements from Solution Sales to Solution Delivery to License Maintenance and Application Support Services. Four levels of competencies were defined (Figure 2).

The initial level defines the core competencies needed by the employee to be hired by the organization and which can be applicable across the different roles in the consulting organization. This includes communication skills and customer service orientation. The second level identifies the General Consulting Skills. This includes the skills needed to understand the client's business processes and their business requirements, and to discuss and present the analysis and recommendations to the client. These two sets of competencies form the General Competencies of the Competency Framework. 


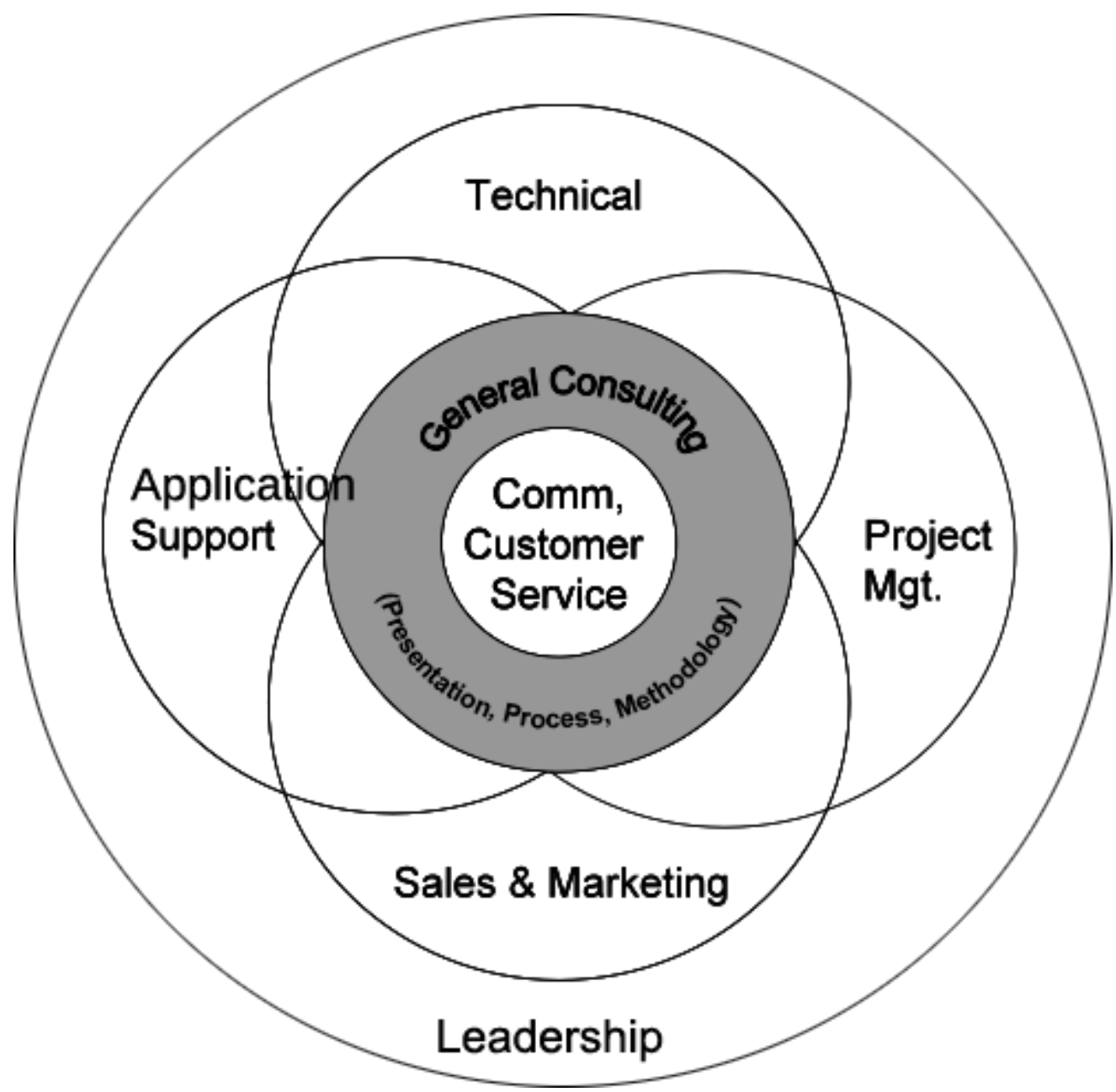

Figure 2. The Proposed Competency Framework

From the general competencies, the framework branches out to four (4) different process areas Sales and Marketing, Project Management, Technical skills, Application Support. This covers the areas following the Service Delivery Methodology - from Sales to Delivery to Support.

Each process area will have their own set of competencies and share common competencies in their areas of intersection. The process starts with Sales and Marketing. Proper understanding of the solutions and their market positioning will help in setting expectations and proper scoping of the solution offering.

After the sales process, it is turned-over to the Project Managers for implementation. Project Management competencies will include managing the project, managing the account and managing all the stakeholders of the project. 
The Project Managers will manage the Project Team composed of the functional and technical consultants. In order to properly manage the consultants, the Project Manager must have an understanding of the business processes and technologies to be deployed in the project. Likewise, the consultants must also have an overview of the Project Management Framework to help them understand the Key Performance Indicators (KPIs) of a successful project.

Once the project is completed, it is turned-over to Application Support. Application Support will share a lot of functional and technical competencies that the consultants have in implementing the project. As such, they will share the technical and application management tools available from the technology provider. Understanding and acquiring skills in using these tools will facilitate the early and successful resolution of the issues received by the Application Support Team.

As the baton is passed from Project Implementation to Application Support, the responsibility of managing the account is turned-over as well. Taking care of the customer's requirements and being present in the account translates to continued business with the client. Opportunities for additional business are then passed on to the Sales and Marketing process and the cycle is repeated.

On top of each track will be the Leadership track. This means that each area requires leadership qualities to move up the competency ladder and into the management track. All areas - Core Competencies, General Consulting Skills, Sales and Marketing, Project Management, Technical and Support will have its own set of competencies and will be presented with their own Job Designs. The Technical area, because of its scope, will expand to various tracks applicable to the clients' business processes. These tracks are Finance, In-bound Logistics, Out-bound Logistics, Manufacturing, Supplier Relationship Management, Human Capital Management, Analytics, Programming and Interfaces, System Administration, Industry Solutions and Supply Management.

All these competency areas taken together form the proposed Competency Framework for an ERP Solution Implementation company.

An example of the Competency Model for the Technical Track and Project Management track is shown in Figure 3 and 4 respectively. 


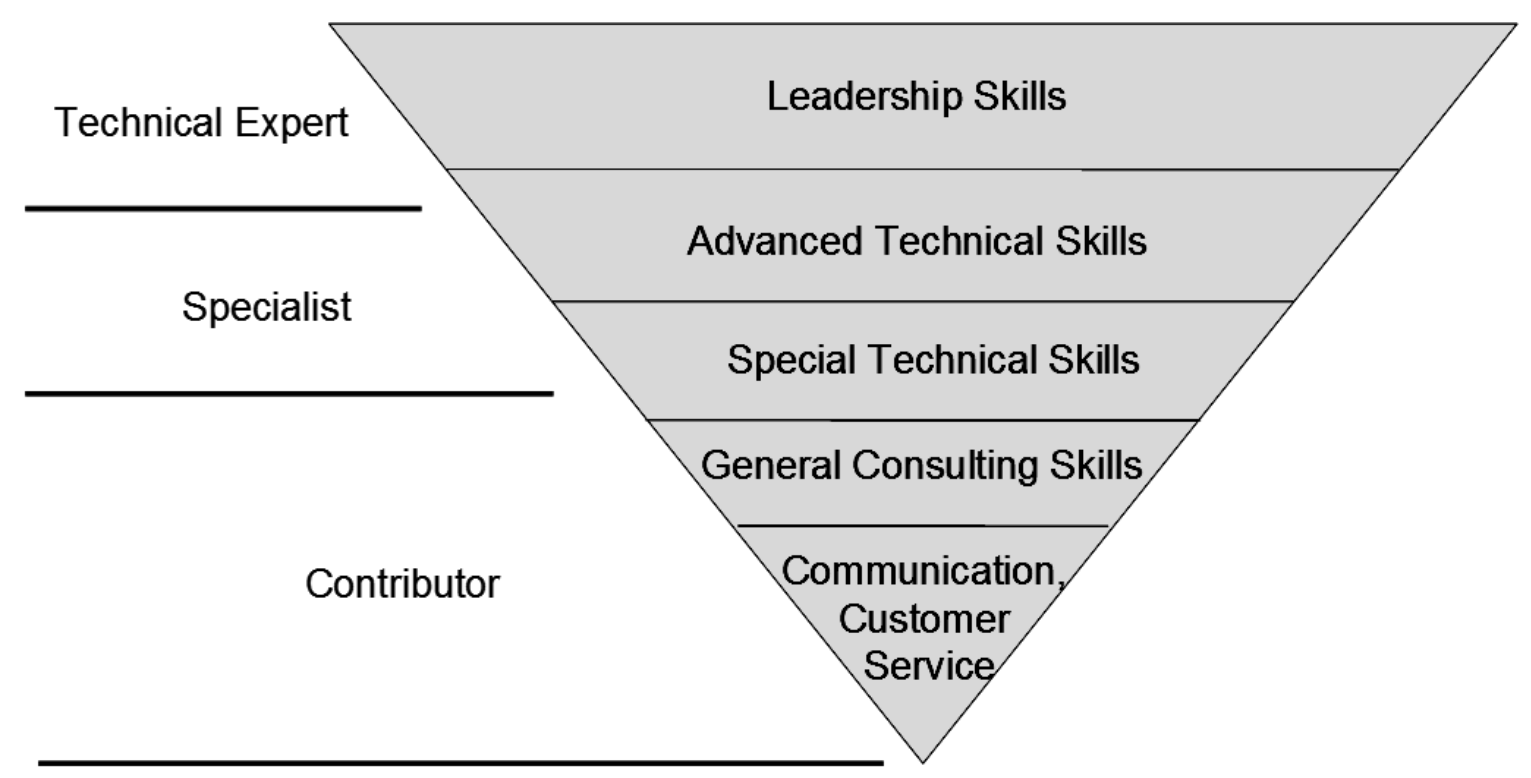

Figure 3. Technical Track Competency Model

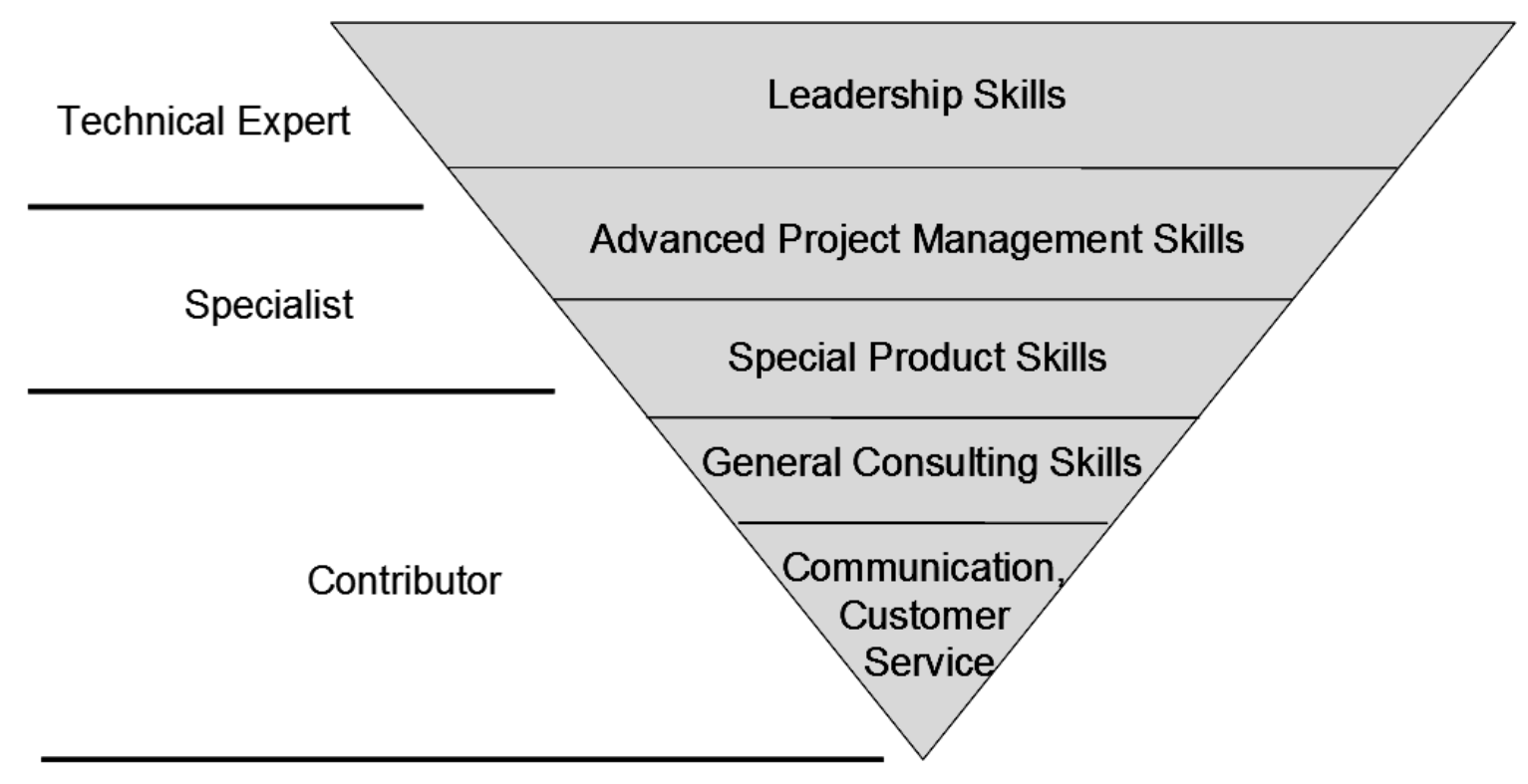

Figure 4. Project Management Competency Model

These Competency Models show the building blocks of skills development from Contributor level to Specialist and Technical Expert / Process Leader levels. It is depicted in an inverted triangle to show that the bigger weight falls under leadership skills. It emphasizes the importance of behavioral and leadership competency in the skills development and career growth of an employee as he moves from the basic communication and customer service skills to basic 


\section{Proceedings of 2013 International Conference on}

Technology Innovation and Industrial Management

29-31 May 2013, Phuket, Thailand

technical skills to advanced technical skills until he takes on the leadership role of a track lead or process lead.

\section{Career Bands and Career Zones}

The Competency Framework not only identifies the competencies within the process areas and functions across the Implementation Methodology. It also provides a structure to move up the competency ladder. The competency-based Performance Management and Career Development Program supports and reinforces the Competency Framework. Its rationale is to take performance management a step forward towards increasing the competitiveness of the firm in terms of increased speed and high quality of service to its clients. This program allows the organization to:

- Develop Talents from Within

- Rationalize Investments

- Identify activities that target results, and

- Build for the future

The Career Development Guiding Principles:

- Prioritize career development activities that directly link to business objectives

- The training and development approach will utilize existing, new and innovative methodologies to deliver learning

- Staff development is crucial in building a pool of future leaders and specialists, as such, managers will be evaluated based on the development of their subordinates

- Reward people who welcome, seek and contribute in building their own and other employee's talents

- Provide employment security based on the individuals' performance and competencies, the business objectives and the organization's directions

Following the Guiding Principles above, the Career Development and Management Framework was formed (refer to Figure 5). It shows how the company's Mission and Vision statements are cascaded to respective objectives of a Business Unit and Functional area. Within each functional area, the process of staffing and selection is mapped across the performance management system. The components of performance management system include both the behavioral/leadership and the technical competencies and how it is translated to an individual's performance through the Key Performance Indicators (KPIs). This Competency Framework then serves as the backbone of the Career Development Program. With the identification of the competencies within each role or function in the organization, high potentials can be identified and developed faster. The corresponding pay scale can likewise be identified and aligned to the career path. 


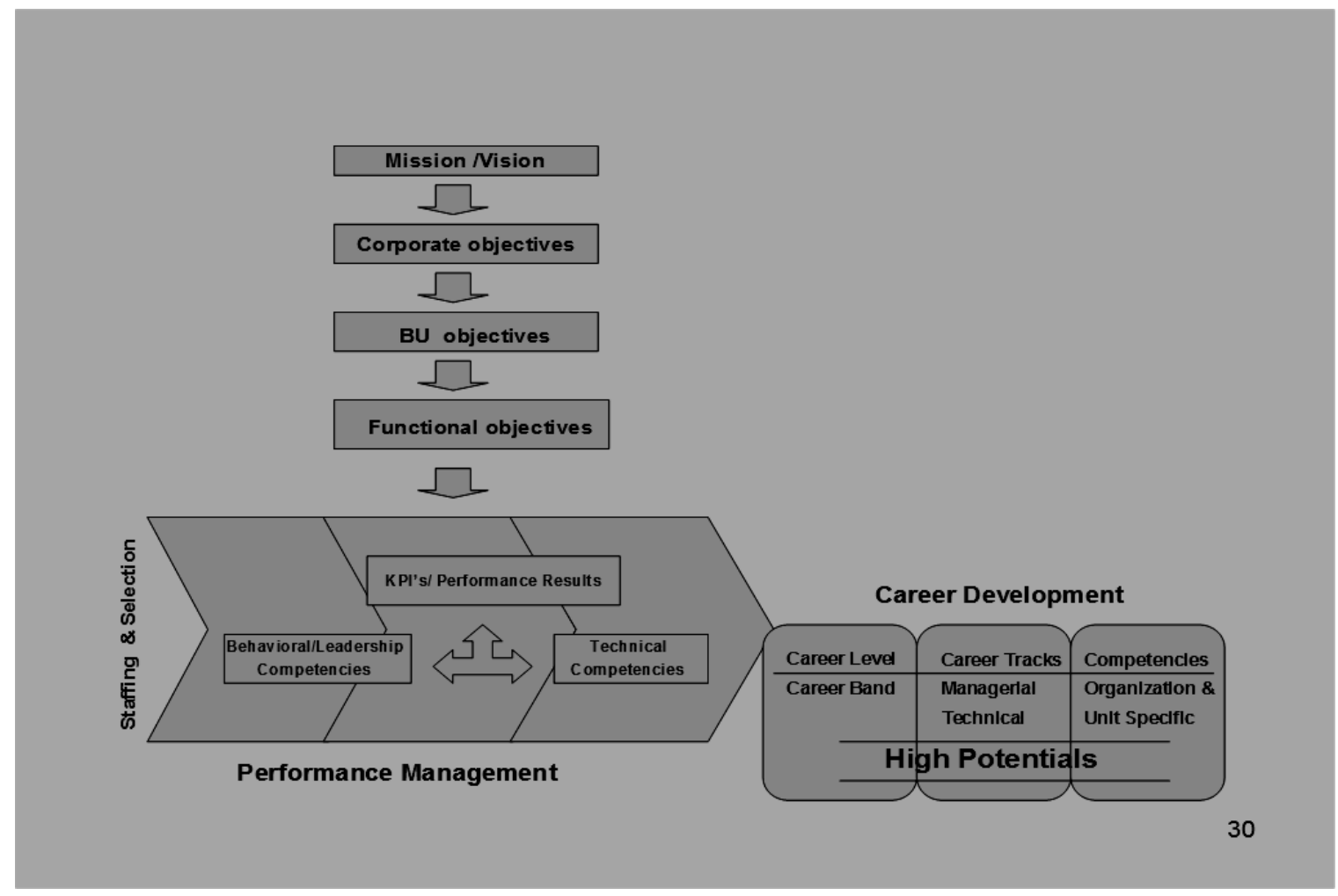

Figure 5. Career Development and Management Framework

There are four (4) career bands - Contributor, Specialist, Technical Expert and Authority/Consultant (refer to Figure 6). Contributor is the entry level for the job. The Contributor exhibits application of skills in developing and implementing solutions to commonly anticipated programs, impacts team goals thru own independent work in contribution to team effort. As one increases technical competency in the job and can assume a team lead or supervisory role, he moves up to the Specialist career band. The Specialist employs training and broad experience in solving complex problems, influence company goals, tactical plans and programs His work significantly impacts group/division goals, can coach or train others. As the technical competency is further increased and leadership and mentoring skills further developed, he moves up to the Technical Expert band. The Technical Expert advises senior management to pursue technical directions, work significantly impacts own group /division/ goals and other major groups/divisions, and can design/innovate major programs and processes. Further up the career ladder is the Authority/Consultant level. Being at this level significantly influences company direction, policy, mission and vision. His decision and actions impact the direction of the entire company. 


\section{Career Track}

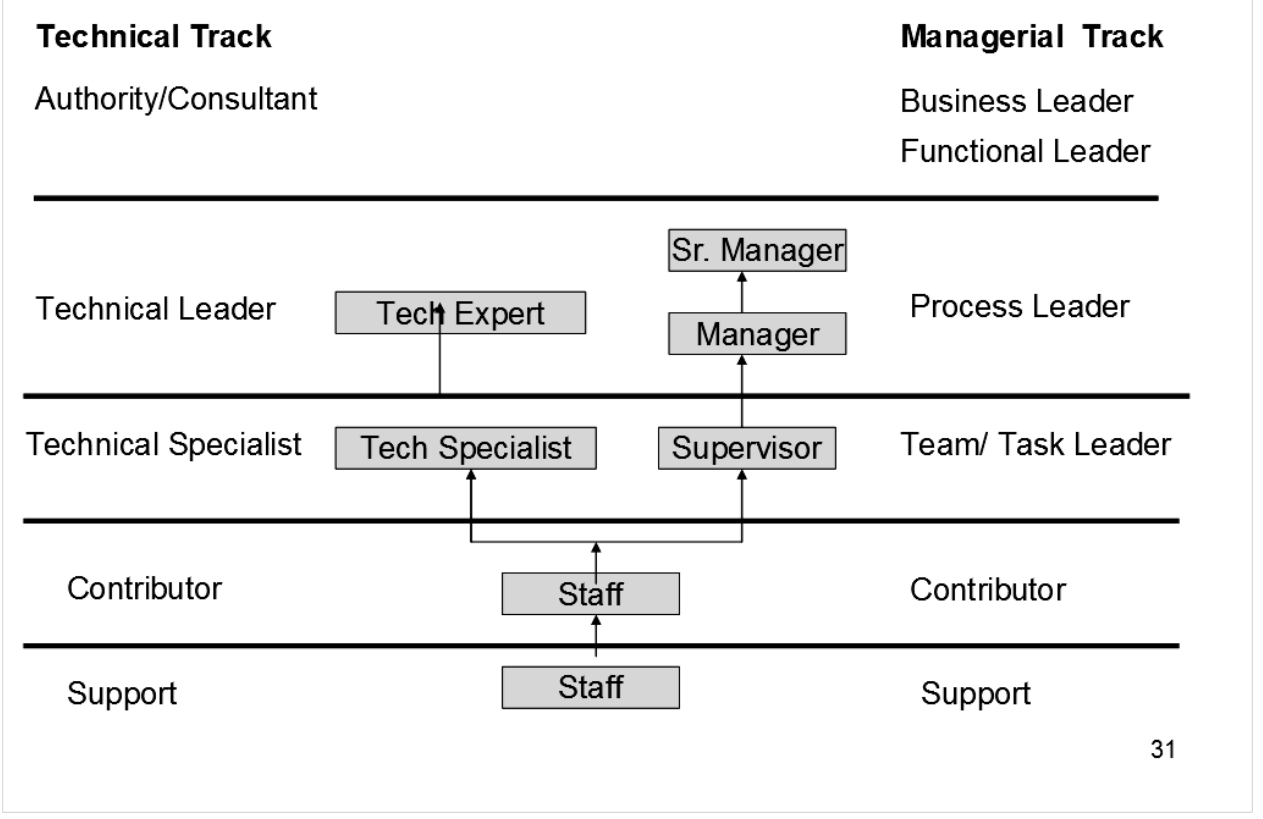

Figure 6. Career Tracks

Within each career band there are three (3) career zones, namely - Learning, Competent and Mature. The Learning zone is the entry point of a career band. It is where the employee gets introduced to the career band and learns the competencies required of that career band. The Competent zone is when the employee gets to display the competencies he learned at the expected proficiency level. As the employee masters the competencies of the career band and is able to apply it in a wide variety of situations without assistance, he qualifies for the Mature zone. Then the employee goes thru these three career zones all over again when he moves to the next career band where he learns, becomes competent and matures in the job and is ready to move to the next career band again.

\section{The Job Design}

Job design involves envisioning and defining the specification of work systems related to a particular job. It is an activity to ensure that people and other resources are effectively and efficiently utilized in delivering quality service and system implementations. Job design is undertaken, keeping in mind job satisfaction and performance, not only from the point of view of the organization but from the clients it serves. The Job Design should be validated annually for the first three years to determine its effectiveness and impact on the quality of service to the clients. 


\section{Proceedings of 2013 International Conference on}

Technology Innovation and Industrial Management

29-31 May 2013, Phuket, Thailand

Each process area will have its own set of competencies per career band and career zone. These will be reflected in their respective Job Designs. A Job Design details the list of competencies relevant to a specific job or role and their corresponding level of importance as well as the expected proficiency level as the person moves up the career ladder. The Job Design is the scorecard that indicates the minimum score for each career zone within each career band. The score is the sum of the weighted proficiency level (importance level multiplied by the rated proficiency) The Importance Level ranges from 1 to 3 with 3 being the highest level. The Proficiency level ranges from A to D with the numerical equivalence of 1 to 4 .

The Proficiency Level is the expected performance of an individual at a certain level. The four (4) levels are A to D as detailed below.

(A) Conceptual knowledge - understands concepts but infrequently applies knowledge; familiarity with terminologies gained thorough readings, briefings, observations; application of basic knowledge or overview; minimal judgment and analysis required (WHAT)

(B) Working knowledge - applies knowledge and experience to mostly routine situations; application of working and functional knowledge and capability in a particular process or method; perform independent action according to acceptable standards and guidelines, may require minimal assistance in unfamiliar situations (WHAT AND HOW)

(C) Thorough knowledge - consistently applies thorough knowledge and experience to a wide variety of situations; has hands-on competence in content area, able to troubleshoot many or most situations without assistance, demonstrates professional discernment and judgment when appropriate (WHAT, HOW, WHY AND WHAT IF)

(D) In depth expertise - high degree of mastery in content area, specialized knowledge enabling advanced analysis and problem solving, innovates, designs systems, processes and approaches, influences critical decision and actions through application of expert opinion and advice (TEACH AND INNOVATE)

The Job Design serves as the guide in rating the current employee's competency level and identifying the areas for improvement and training needs to move him to the next career zone and/or the next career band. The Job Design is a very useful tool in performance evaluation as well as employee selection and recruitment.

In order to balance the competencies per track, alignment of the competency blocks and descriptors will be done so as to group them and come up with equivalences. This will allow the competencies or groups of competencies to total to an equivalent number. This will then serve as a guide for cross-training and up-training. The expansion of competencies will contribute to the increase in job scope and expertise of the consultants for their career development and the company's competitive advantage in delivering cost effective quality service to their clients 


\section{Proceedings of 2013 International Conference on}

Technology Innovation and Industrial Management

29-31 May 2013, Phuket, Thailand

\section{The Training Plan}

A training plan is a component of a company's training system. A company's training system identifies and addresses the training needs of the company aligned with the company's objectives. It covers a four-tiered analysis of the company's training needs namely - an organizational analysis, a job analysis, a person analysis and a client-needs analysis.

An organizational analysis is used to identify company factors that can impact the effectiveness of the training program, such as the training budget.

A job analysis is the process of identifying the skills to be learned and training activities required to successfully perform a job. The Training Plan is a document that details the training and certification requirements for each job. It involves an examination of the tasks involved in each job and the identification of the corresponding training objective. The objective should identify what the skill is, how the trainee is to learn the skill and how proficient the trainee needs to be in the skill after the training is completed. The Training Plan is needed to maintain a common standard of training for all employees for performance assessment and a guide to employees of the company's expectations.

A person analysis is the identification of the employees needing training and what specific training they need. Input from the past and current performance appraisals and competency assessments are used to identify the specific employee's training needs and individual Training Plan. The Performance Appraisal Form is used for both mid-year and annual performance assessment as well as employee regularization assessment. Citations and areas for improvement are indicated and serve as input to identifying the individual's training needs for the next period.

A client needs analysis is geared towards identifying the core competencies needed to address and deliver, not just quality customer service, but excellent customer service. This is a critical aspect that needs to be considered in the company's competitive strategy. The company gets feedback from the client through the Customer Satisfaction Survey forms to be given at the end of the project. Client assessment is taken for the Project Manager and the consultants. A Training Plan imbedding excellent customer service should be covered by the company's corporate training program. These are the soft skills complementing the technical, project management and support service competencies.

Even sales and marketing, instinctively geared towards customer service, will benefit from this. It is not uncommon that technical people transition to pre-sales then to sales and marketing. Corporate training encompassing communication and presentation skills development, general consulting skills and excellent customer service will support the employees' career development and provide options for the employees who may want to shift careers. But more importantly, the focus on understanding the clients' needs and the level of service needed to address those needs is a key component of the Training Plans. 


\section{Proceedings of 2013 International Conference on}

Technology Innovation and Industrial Management

29-31 May 2013, Phuket, Thailand

\section{METHODOLOGY}

The Career Development and Management Frameworkfollows the Organizational Development Framework. With this, the general Competency Framework of the Implementation Methodology should be developed. From the feedback of the clients and the lessons learned in previous projects, the study looked at Structures, Processes and the People components of Organizational Change Management as follows:

\section{Structure Development}

The components of the Structure Development are:

a. Identification of the different technical tracks

b. Research on the technical competencies as the initial set

c. Validation and refinement

d. Creation of the Job Designs

e. Development of the Training Plans

The development of the structure was initially based on the different modules of the SAP System. From there, the competencies were expanded to include the understanding and knowledge of the business processes they support and the rationale for such competencies. The structure was enriched by the input from the clients and results of the Quality Assurance (QA) checks done on previous projects.

\section{Process Development}

The components of the Process Development are:

a. Competence Assessment

b. Recruitment and Selection

c. Performance Evaluation

The process of using the Job designs from recruitment to performance evaluation and career development should be tested and continue to be validated through the results of the projects implemented. It is an iterative process and should be validated at least once a year.

\section{People Development}

The components of the People Development are:

a. Human Resource Team

b. The consultants

c. The Management Team and Track Leads

Input from the validation of Process Development above feeds the human resource development - from the consultants/employees to the track leads and the management team to the entire organization. 


\section{Proceedings of 2013 International Conference on}

\section{SUMMARY, VALIDATION AND RECOMMENDATIONS}

Organizational Development is the process through which an organization develops the internal capacity to be the most effective in its mission work and sustain itself over the long term. Input from and collaboration with partner organizations and clients in Organization Development initiatives will bring competitive advantage. Organizational Development is a long and tedious process but is essential in the growth and success of any organization and the organizations of their customers. The Chief Executive Officer or Executive Director's role is vital to the success of any organizational development work. And the involvement of the board, management team and staff, partner organizations and clients is essential. The stakeholder base for organizational development work should be extended not only to clients but to the academia involved in national competitiveness and productivity improvement as they provide the input to the human supply chain. Organizational Development is a never-ending process so pacing the work is wise.

This study on the Building Blocks of Consulting Service Excellence focused on the Competency Framework and Human Resource Development and tested on the SAP Technology in an ERP Solution Implementation company. It covered the processes from Sales to Delivery to Support on the conceptual level. The execution was limited to the technical tracks. Job Designs were done for four (4) sample tracks - Financial Accounting and Controlling, Supplier Relationship Management, Analytics and System Administration. These tracks were chosen as they represent the different SAP solutions and services, namely, the core Enterprise Resource Planning (ERP) solution, the extension solutions, the Business Consolidation and Enterprise Reporting solution, and the Technical Services. Financial Accounting and Controlling falls under the core ERP solution. Supplier Relationship Management falls under the extension solutions, Analytics is the business Consolidation and Enterprise Reporting solution while System Administration is one of the SAP Technical Services.

The Training Plans were likewise developed for each sample track and accomplished for each employee within that track and eventually, for the entire organization. This then serves as a guide for both the Track Lead and Human Resources to schedule the training courses and list the attendees accordingly. It also informs the employee ahead of time to plan for these training courses and certification requirements he is expected to complete within the year. These requirements are part the Organizational and Personnel Development component of his Key Performance Indicators (KPI) for the year.

The Job Designs and Training Plans of the selected pilot tracks were completed and validated. The Competency Profile of each track was used to identify competency gaps and determine which will be filled through recruitment, up-skilling through training or cross-training from other tracks. The results were also used as basis for salary upgrades and promotions. The Job Designs are also used to assess applicants with prior SAP experience and determine if their competency level falls under the requirements of the track. Job offers are then more aligned to the competency levels. 


\section{Proceedings of 2013 International Conference on}

Technology Innovation and Industrial Management

29-31 May 2013, Phuket, Thailand

In sum, the Competency Framework has been very helpful in the proper assessment of skill levels of both employees and applicants. It is a very objective approach to performance assessment and a good basis for determining the compensation and benefits packages offered to employees as it is very much aligned with the revenue performance of each track.

The Competency Framework has also been well received by the employees as it provides a clear guide to career development and growth and a proactive approach to excellence in service delivery to the clients. It benefits the individual employees with the structured approach to skills development and learning. It benefits the leadership of the organization with the alignment of the Competency Profile and the Revenue targets and a vital input to Resource Loading and Management. This will also impact the organization's culture with emphasis on performance and value and provide the needed structure and processes to support the company's performance goals.

The Competency Framework is also expected to benefit clients and partners in terms of providing the appropriate skill level of the consultants assigned to deliver the company's services to the clients. With the proper alignment of the competency levels with the contracted service to be delivered to the client, there should be an increase in the success rate of projects and an increase in customer satisfaction. Happy customers translate to repeat business and client referrals which hopefully translate to increased business and the company's growth and success.

\section{REFERENCES}

1. Buban, C.E., (2013), "Growing KPO market to spur homebuilding outside Metro Manila”,Philippine Daily Inquirer,11January,http://business.inquirer.net/102255/growingkpo-market-to-spur-homebuilding-outside-metro-manila/ (accessed 10 March, 2013).

2. Harvard Business School. (n.d.). "Competitive strategy", http://www.isc.hbs.edu/firmcompetitve.htm/(accessed 15 January, 2013).

4. "Knowledge process outsourcing - KPO", (2013), Investopedia. http://www.investopedia.com/terms/k/knowledge-processoutsourcing.asp\#axzz2NKq47nAj/ (accessed 10 March, 2013).

5. "Knowledge process outsourcing (KPO)", (2013), BusinessDictionary.com. http://www.businessdictionary.com/definition/knowledge-process-outsourcingKPO.html/(accessed 10 March, 2013).

6. Mind Tools, (2013),“Developing a competency framework",http://www.mindtools.com/pages/article/newISS_91.htm/(accessed 10 March, 2013).

7. MMS Institute, LC, (2011),"Management consulting",http://www.themms.com/corporateeducation?id=109/ (accessed 17 November, 2012). 